\title{
Kinetics and products of air plasma induced oxidation in water of imidacloprid and thiamethoxam treated individually and in mixture
}

\author{
Francesco Tampieri, Alessandro Durighello, Omar Biondo, Marcelina Gasior, Aleksandra Knys, \\ Ester Marotta*, Cristina Paradisi \\ Department of Chemical Sciences, University of Padova, via Marzolo 1, 35131 Padova, Italy \\ ester.marotta@unipd.it, +390498271608
}

Imidacloprid (I) and thiamethoxam (T) are widely used neonicotinoid insecticides with high persistence in the environment and thus included in the watch list of substances for European Union-wide monitoring reported in the Decision 2015/495/EU. In this work we report and discuss the results of a study in which aqueous solutions of $\mathrm{I}, \mathrm{T}$ and $\mathrm{I}+\mathrm{T}$ were subjected to advanced oxidation by air plasma produced by negative DC corona discharges above the liquid surface. The oxidative degradation of each pollutant was investigated by monitoring the rate and the products of its decay when treated alone and in the presence of variable amounts of the other compound. The results show that both $\mathrm{I}$ and $\mathrm{T}$ are readily degraded and that mineralization can be achieved in this process, as proven by the measurement of the residual organic carbon and by the quantitative conversion of chlorine and sulfur into inorganic chloride and sulfate, respectively. The major organic intermediates formed during the complex stepwise oxidation of I and $\mathrm{T}$ were identified and monitored by HPLC-MS/MS analysis. The results of kinetic studies show that both for I and $\mathrm{T}$ the reaction rate depends inversely on the insecticide initial concentration, that $\mathrm{I}$ and $\mathrm{T}$ have similar reactivities and that they do not interfere reciprocally in any specific way when treated in mixture at a total concentration of $c a 10^{-4} \mathrm{M}$. Based on literature data and on previous results with the same reactor, it is reasonable to propose that the oxidation of $\mathrm{I}$ and $\mathrm{T}$ is initiated by the reaction with $\mathrm{OH}$ radicals.

Keywords: imidacloprid, thiamethoxam, non-thermal plasma, mixture, mineralization

\section{1 - Introduction}

Neonicotinoids, first introduced in 1991, have steadily replaced the older classes of organochlorine, organophosphate and carbamate insecticides and are presently the most important family of insecticides on the market [1]. Their desirable properties include broad-spectrum insecticidal activity, persistent effect and systemic nature [2,3]. Due to their high water solubility and persistence in soil, however, neonicotinoids represent a threat of water contamination. Thus, despite a widespread consensus on the fact that neonicotinoids should pose low risks to fish and mammals $[4,5]$, their effects on aquatic ecosystems and on human health are yet to be fully ascertained. Neonicotinoids are persistent in waste water treatment plants and constructed treatment wetland and 
significant amounts have been found in the aquatic ecosystems in various countries [6] and also in tap water [7]. Therefore, neonicotinoid pesticides, including imidacloprid (I) and thiamethoxam (T), the two compounds considered in this work (Chart 1), are listed in the watch list of substances for European Union-wide monitoring reported in the Decision 2015/495/EU [6]. And, not surprisingly, there are numerous recent studies dealing with the degradation of neonicotinoid insecticides in water, specifically of imidacloprid and thiamethoxam, by various advanced oxidation processes (AOPs), mostly by UV [8], photocatalytic [9], UV/chlorine [10], photo-Fenton [11], electrochemical [12], electro-Fenton [13, 14] and ozonation processes [15]. Specifically, the photoassisted degradation of imidacloprid was studied under different conditions [16-20], including also treatment in a pilot-scale plant by photolysis with Fe(III)-EDDS as complexing agent [21]. Similarly, recent papers report on the degradation of thiamethoxam induced by ozonation [22], UV [8], UV, ozone and UV/ozone [23], and photocatalysis in aqueous suspension of TiO2 [24].

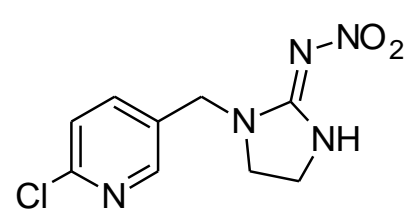

Imidacloprid (I)<smiles>CN1COCN(Cc2cnc(Cl)s2)/C1=N/O</smiles>

Thiamethoxam (T)

\section{Chart 1}

Among the novel AOPs being considered and developed for water and wastewater treatment ([25] and references therein), non-thermal plasma (NTP) is being actively pursued as a means to activate the degradation of recalcitrant organic pollutants. Depending on discharge type and energy, reactor design and other experimental conditions, NTPs in air/liquid water systems may expose organic pollutants dissolved in water to the effect of various very reactive species, ROS and RNS, excited molecules, solvated electrons and photons [26]. In the above cited very recent critical review, plasma based processes are listed among those which presently are likely too energy intensive for most practical applications but "might still provide attractive solutions for specific challenges and full-scale applicability of these processes should be further investigated" [25]. Encouraging results have indeed been obtained with small lab-scale prototype NTP reactors of different design and configuration, which are described and classified in recent review articles [26-28]. Discharge conditions and reactor design are indeed major issues in the development of efficient NTP based technologies and research is very active in this field [29] also in our laboratory [30-33]. A recent interesting paper on NTP induced degradation of most recalcitrant perfluoroalkyl substances 
suggests that reactor design and experimental conditions should be tailored and optimized for treatment of the specific target class of organic pollutants [34].

Many different prototypal NTP setups have been tested to treat an array of organic compounds in water ranging from humic substances, used as models of dissolved natural organic matter [35], to organic pollutants including, to cite a few important classes, pharmaceuticals [36, 37], dyes [38, 39], perfluoroalkyl substances [34] pesticides [40-42]. As for imidacloprid and thiamethoxam, the neonicotinoids used in this work, to the best of our knowledge there is only one paper in the literature reporting on NTP treatment of a $0.34 \mathrm{mM}$ solution of thiamethoxam with dielectric barrier discharge in the presence of $\mathrm{TiO}_{2}$ [43]. A removal rate of $86 \%$ was achieved in 160 min with a discharge power of $150 \mathrm{~W}$. Product analysis was carried out by HPLC-MS and speculative structures and mechanisms of formation have been arbitrarily proposed for the detected species. No data are reported on the extent of mineralization achieved, i.e. conversion of all organic carbon to carbon dioxide [43]. Obviously, this is a crucial issue for NTP based treatments, as well as for any other AOP. It could be argued that complete mineralization may not necessarily be the ultimate goal of NTP processing, since the organic intermediates formed from the original recalcitrant pollutant, especially those in the late stages of the degradation path, i.e. short chain carboxylic acids, should be amenable to oxidation in the traditional water treatment processes. Although reasonable, this expectation should however be verified experimentally, a formidable, practically impossible task. Indeed numerous examples are known of oxidation intermediates which are more toxic than the precursor pollutant $[44,45]$. Another most important aspect still to be investigated is the matrix effect. Most published studies deal with the treatment of individual pollutants in artificial solutions and very little information is available on the behavior of organic pollutants treated in more complex matrices like natural waters and waste waters containing many different pollutants. Aim of this investigation was to contribute to this area by studying the behavior of the two important neonicotinoids imidacloprid and thiamethoxam when treated individually and in mixture in a well characterized NTP reactor we developed and tested previously [33, 42].

\section{2 - Experimental section}

\section{1 - Materials}

Imidacloprid (>98\%), thiamethoxam (>98\%), formic acid (98\%), methanol (99.9\%), sodium carbonate $(>99 \%)$, sodium bicarbonate $(>99.5 \%)$, sodium sulfate $(>99 \%)$, sodium chloride $(>99 \%)$ and potassium hydrogen phthalate $(>99 \%)$ were purchased from Sigma-Aldrich. Ultrapure grade water (milliQ water) was obtained by filtration of deionized water with a Millipore system. Pure air 
used in the experiments was a synthetic mixture (80\% nitrogen and $20 \%$ oxygen) from Air Liquide with specific impurities of $\mathrm{H}_{2} \mathrm{O}(<3 \mathrm{ppm})$ and of $\mathrm{C}_{\mathrm{n}} \mathrm{H}_{\mathrm{n}}(<0.5 \mathrm{ppm})$.

\section{2 - Experimental apparatus}

The configuration of the experimental set-up employed in this work has been described in detail in [33] and [42]. The reactor is a container made of Plexiglass with dimensions 360x149x53 mm, closed hermetically with a Plexiglass top. The effective volume of the reactor is $2112 \mathrm{~mL} ; 170 \mathrm{~mL}$ are occupied by the solution to be treated and the remaining $2092 \mathrm{~mL}$ by air. The active electrode ( 7 electrically connected parallel wires) are mounted in the reactor top and are connected to the power supply. The counter electrode, constituted by a steel plate (1.5 mm thickness), is in the reactor base, in contact with the solution, and is connected with a system for the measurement of the electric current and to the ground. The reactor top has three ports, one for the gas inlet, one for the gas outlet and the third, with a silicon septum, for sampling the solution.

The reactor was energized by a negative DC voltage $(-9.5 \mathrm{kV})$ provided by a Spellman PTV30 power supply. We used two multimeters to measure the voltage and current signals every 5 minutes. The power of the reactor was calculated as the product of voltage and current. Since the instantaneous power was not always constant during the experiment, we calculated an average power weighted on the treatment time for each experiment. The average power was $5.5 \mathrm{~W}$ but a variability of $\pm 1 \mathrm{~W}$ was observed in different experiments performed under the same experimental conditions. Energy was obtained as the product of the averaged power multiplied by the treatment time.

During the experiment, synthetic air was flown through the reactor. Before entering the reactor the air was humidified to prevent evaporation of the solution from the reactor.

\section{3 - Analytical procedures}

Mother solutions $\left(1 \cdot 10^{-3} \mathrm{M}\right)$ of imidacloprid and thiamethoxam in milliQ water were diluted to achieve the desired concentration to used in the plasma experiments. In the experiments in which we treated mixtures of the two pollutants, we prepared solutions with a total concentration equal to ca $1 \cdot 10^{-4} \mathrm{M}$ and varied the relative amounts of the two pollutants.

The actual concentrations of the solutions used for the experiments, as well as the pollutants residual concentrations as a function of the plasma treatment time, were obtained by HPLC/UV-Vis analysis.

For the experiments in which the pollutants were treated individually, we used a Thermo Scientific Products instrument with a P2000 pump and an UV600LP Diode array detector, a Phenomenex 
Kinetex EVO C18 column (5 um, 100 A, 150x4.6 mm) and a mobile phase composed of water with $0.05 \%$ of formic acid (A) and methanol with $0.05 \%$ of formic acid. The LC gradient for the analysis of thiamethoxam was: from 0 to $5 \mathrm{~min} 5 \% \mathrm{~B}$ isocratic, from 5 to $15 \mathrm{~min}$ a linear increase of B from 5 to $60 \%$, from 15 to 17 min $60 \%$ B isocratic, initial conditions were reestablished in 5 min. The LC gradient for the analysis of imidacloprid was: from 0 to $25 \mathrm{~min}$ a linear increase of $\mathrm{B}$ from 5 to $70 \%$, from 25 to $27 \mathrm{~min} 70 \% \mathrm{~B}$ isocratic, initial conditions were reestablished in $5 \mathrm{~min}$. The eluition was followed at $250 \mathrm{~nm}$ for thiamethoxam and at $270 \mathrm{~nm}$ for imidacloprid. The flow rate was 1 $\mathrm{mL} / \mathrm{min}$.

For the analysis of the experiments in which the pollutants were treated in mixture we used a Agilent 1260 Infinity II instrument (G7112B Binary Pump, G7129A Autosampler, G7114A VWD detector) a Agilent InfinityLAb Poroshell 120 EC-C18 (2.7 um, 3.0x150 mm) and a mobile phase composed of water with $0.1 \%$ of formic acid (A) and acetonitrile with $0.1 \%$ of formic acid. The LC gradient for the analysis was: from 0 to $1 \mathrm{~min} 5 \% \mathrm{~B}$ isocratic, from 1 to 8 min linear increase of $\mathrm{B}$ from 5 to $60 \%$, from 8 to $8.5 \mathrm{~min} 60 \% \mathrm{~B}$ isocratic, initial conditions were reestablished in $1.5 \mathrm{~min}$. The flow rate was $0.6 \mathrm{~mL} / \mathrm{min}$.

Standard solutions of imidacloprid and thiamethoxam prepared at known concentrations were used for calibration of both HPLC instruments.

The solution $\mathrm{pH}$ and conductivity were measured, in all experiments, before and after plasma treatment using a a Mettler-Toledo S220 pH-meter equipped with an InLab Versatile Pro electrode and a Metrohm 660 Conductometer equipped with a 6.0901 .130 electrode respectively. In agreement with observations reported previously (42), after a $5 \mathrm{hr}$ plasma treatment the solution $\mathrm{pH}$ had dropped from neutral to about 2.8-3.0 in all experiments performed, with one or two pollutants as well as with ultrapure water used as control. The acidification of the medium is due to $\mathrm{HNO}_{3}$ formed by reaction of plasma generated $\mathrm{NO}_{\mathrm{x}}$ as detailed in ref. 42. As for the solution conductivity, following $5 \mathrm{hr}$ plasma treatment it increased from the very low values of all untreated solutions (a few units - tens of $\mu \mathrm{S} / \mathrm{cm}$ ) to about $450 \mu \mathrm{S} / \mathrm{cm}$ in the case of ultrapure water and to somewhat higher values $(500-650 \mu \mathrm{S} / \mathrm{cm})$ in the case of pollutant containing solutions.

The efficiency of degradation of the pollutants during plasma treatment was evaluated using the half life time $\left(t_{1 / 2}\right)$, obtained by interpolation of the residual concentrations as function of the treatment time $(t)$ using the following equation:

$$
\begin{gathered}
C(t)=C_{0} \cdot e^{-k_{t} \cdot t} \\
t_{1 / 2}=\frac{\ln 2}{k_{t}}
\end{gathered}
$$


where $C(t)$ and $\mathrm{C}_{0}$ are the concentration at time $t$ and the initial concentration, respectively, and $k_{t}$ is the decay kinetic constant. However, as $k_{t}$ depends on the applied electrical power, we considered also the energy constant $\left(k_{E}\right)$, obtained by interpolation of the residual concentrations as function of the energy of the treatment $(E)$

$$
C(E)=C_{0} \cdot e^{-k_{E} \cdot E}
$$

The analysis of the oxidation products of the pollutants was done using the same column, eluents and gradients as specified above for the single pollutants experiments but with a different HPLC system (Agilent 1100 Series) connected to a diode array and a mass spectrometer detector (MSD Trap SL model G2245D). The ionization was performed within an electrospray (ESI) source in positive polarity using the following parameters: nebulizer $50.0 \mathrm{psi}$, dry gas flow rate $8 \mathrm{~L} / \mathrm{min}$, dry gas temperature $350{ }^{\circ} \mathrm{C}$, capillary voltage $-3.5 \mathrm{kV}$, capillary exit $128.5 \mathrm{~V}$, skimmer $40 \mathrm{~V}$.

The concentration of chloride and sulfate ions released in solution after the plasma treatment of the pollutants was measured by ion chromatography using a Dionex-ICS-900 instrument equipped with a Dionex IonPac AS22 IC column after proper calibration with standard solutions of sodium sulfate and sodium chloride. $4.5 \mathrm{mM}$ sodium carbonate and $1.4 \mathrm{mM}$ sodium bicarbonate were used as eluent at a flow rate of $1.2 \mathrm{~mL} / \mathrm{min}$ for $15 \mathrm{~min}$.

The total amount of carbon in solution, before and after plasma treatment, was measured using a Shimadzu TOC-VCSN analyzer, equipped with an autosampler and an automatic diluter. The instrument was calibrated using standard solutions of potassium hydrogen phthalate.

\section{3 - Results and Discussion}

\section{1 - Experiments with I and T treated individually}

The effect of the pollutant initial concentration on the NTP process efficiency was investigated first in experiments in which each insecticide was treated individually. The explored range, $1 \cdot 10^{-5}-1 \cdot 10^{-}$ ${ }^{4} \mathrm{M}$, could not be extended to lower concentrations, which would be more consistent with those found in the environment, because under those conditions the reaction rates were too high to be measured by our experimental protocol. The results are displayed in Fig. 1 which reports plots of the pollutant residual concentration $\left(C / C_{0}\right)$ vs energy. It is seen that, as previously found with other organic pollutants treated in the same reactor under the same experimental conditions [42], the pollutant concentration decays according to approximately a first order exponential curve and that the process efficiency depends on the pollutant initial concentration (the lower the initial 
concentration the higher the efficiency). It was also found that the reactivities of I (Fig. 1a) and T (Fig. 1b) are quite similar, as can be best appreciated considering Table 1 which summarizes all energy constant $\left(k_{E}\right)$ and half-life time $\left(t_{1 / 2}\right)$ data. It is interesting to compare the performance of our reactor in the degradation of thiamethoxam with the data reported by $\mathrm{Li}$ et al. [43]. We obtain an energy efficiency (calculated as $\mathrm{G}_{50}$ [46]) equal to $1.70 \mathrm{~g} / \mathrm{kWh}$ for the experiment with thiamethoxam starting concentration equal to $9.2 \cdot 10^{-5} \mathrm{M}$ (average power $4.7 \mathrm{~W}$ ) while $\mathrm{Li}$ et al. have an energy efficiency of about $0.3 \mathrm{~g} / \mathrm{kWh}$ (starting concentration $3.4 \cdot 10^{-4} \mathrm{M}$, average power $150 \mathrm{~W}$ ).
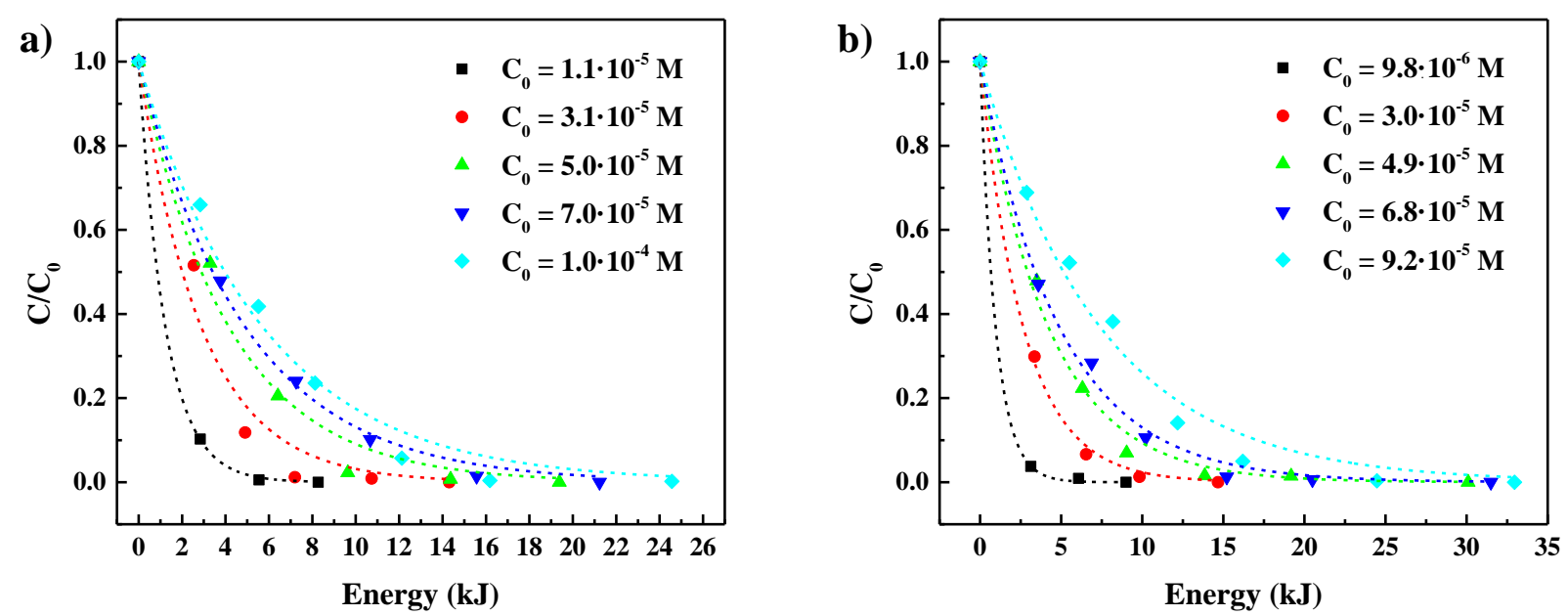

Figure 1. Pollutant residual concentration as a function of energy for experiments with: a) I; b) T. The dashed lines were obtained by fitting the experimental data with a first order exponential function.

Table 1. Energy constant $\left(k_{E}\right)$ and half-life time $\left(t_{1 / 2}\right)$ for Imidacloprid (I) and Thiametoxam (T) decay in NTP advanced oxidation process. ${ }^{a}{ }^{a}$

\begin{tabular}{ccc|ccc}
\hline $\mathbf{I}(\mathbf{M})$ & $\boldsymbol{k}_{\boldsymbol{E}}\left(\mathbf{k} \mathbf{J}^{-\mathbf{1}}\right)$ & $\boldsymbol{t}_{\boldsymbol{1 / 2}}(\mathbf{s})$ & $\mathbf{T}(\mathbf{M})$ & $\boldsymbol{k}_{\boldsymbol{E}}\left(\mathbf{k} \mathbf{J}^{-1}\right)$ & $\boldsymbol{t}_{\boldsymbol{1 / 2}}(\mathbf{s})$ \\
\hline $1.1 \cdot 10^{-5}$ & $0.81 \pm 0.01$ & $182 \pm 2$ & $9.8 \cdot 10^{-6}$ & $1.04 \pm 0.03$ & $127 \pm 5$ \\
$3.1 \cdot 10^{-5}$ & $0.35 \pm 0.04$ & $490 \pm 50$ & $3.0 \cdot 10^{-5}$ & $0.38 \pm 0.01$ & $333 \pm 5$ \\
$5.0 \cdot 10^{-5}$ & $0.24 \pm 0.02$ & $530 \pm 40$ & $4.9 \cdot 10^{-5}$ & $0.24 \pm 0.01$ & $540 \pm 20$ \\
$7.0 \cdot 10^{-5}$ & $0.20 \pm 0.01$ & $560 \pm 10$ & $6.8 \cdot 10^{-5}$ & $0.204 \pm 0.008$ & $580 \pm 20$ \\
$1.0 \cdot 10^{-4}$ & $0.17 \pm 0.01$ & $870 \pm 50$ & $9.2 \cdot 10^{-5}$ & $0.135 \pm 0.008$ & $1130 \pm 70$ \\
\hline
\end{tabular}

a) Details are given in the Experimental Section. 


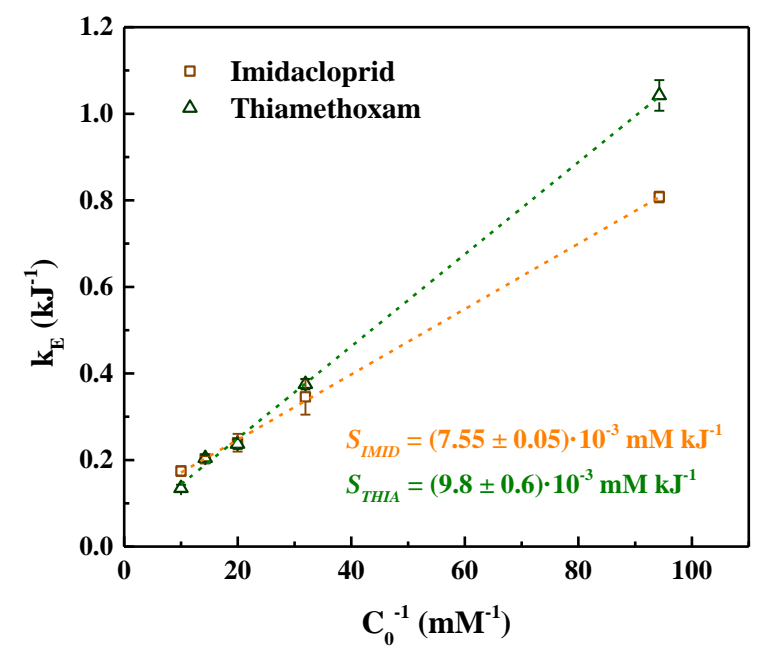

Figure 2. Dependence of $k_{E}$ on $1 / C_{0}$ for I and T subjected individually to NTP treatment.

From the plots in Fig. 2 it is seen that both for I and T the efficiency of the process, expressed by the energy constant $k_{E}$, depends linearly, in first approximation, on $1 / C_{0}$. This behavior is consistent with previous reports in the literature showing that the pseudo-first order rate constant $(k)$ of air non-thermal plasma induced oxidation of organic pollutants depends on the pollutant initial concentration, $C_{0}$, and often increases linearly with increasing $1 / C_{0}[32,47,48]$. Such a dependence is predicted, under some approximations, by a simple kinetic model based on a mechanism of inhibition by products proposed by Slater and Douglas-Hamilton [49]. Thus, it is expected that the process should be highly efficient for treatment of very dilute solutions, as are generally found in the environment. Moreover, according to the Slater and Douglas-Hamilton model, the slope $(S)$ of the $k$ vs $1 / C_{0}$ linear plot is the rate of formation, assumed to be constant by the model, of the reactive species responsible for the pollutant decay. The fact that the slopes in the two plots of Fig. 2 are similar, therefore, suggests that the reactive species involved in the oxidation rate limiting step are the same for I and $\mathrm{T}$.

The high efficiency of the process observed at low pollutant concentrations made it possible to achieve within a reasonably long treatment time the mineralization of all organic matter, i.e. the complete degradation not only of the pollutant itself but also of its organic products formed en route to $\mathrm{CO}_{2}$. Relevant results are summarized in Table 2 which reports the extent of mineralization found for I and T, each treated individually for the same time $(5 \mathrm{~h})$ at two different initial concentrations, $1 \cdot 10^{-5}$ and $1 \cdot 10^{-4} \mathrm{M}$. The data are based on TOC and ion chromatographic analyses which allowed us to determine, respectively, the amount of residual organic carbon in solution and the conversion of chlorine and sulfur into their inorganic ions, $\mathrm{Cl}^{-}$and $\mathrm{SO}_{4}{ }^{2-}$. The corresponding quantitative determination of mass balance of total nitrogen was prevented by the high background of nitrate 
derived from plasma produced NOx. The data reported in Table 2 show that both I and T undergo complete mineralization when present at $1 \cdot 10^{-5} \mathrm{M}$ initial concentration. This result is quite encouraging for technological developments of this approach for treatment of contaminated waters in which the concentrations of these pollutants are much lower (below nM [1]). Thus, based on the findings described above (Fig. 2) it is expected that mineralization should be achieved at these low concentrations in relatively short times and at affordable energy costs. Also reassuring is the selfconsistency of the results obtained by independent and quite different types of analyses monitoring carbon, chlorine and sulfur in the treated solutions. The mineralization yield achieved in the case of more concentrated solutions treated in the NTP reactor for the same time is considerably lower, despite the fact that the original pollutant, I or T, was completely converted at this reaction time. It was therefore of interest to analyze the solution at various treatment times to detect and identify the organic products formed, from which possibly also gain insight into the mechanism of the reaction. These analyses were performed by means of HPLC-MS-MS procedures as detailed in the experimental section. A typical chromatogram showing the complexity of the reaction mixture obtained after a $30 \mathrm{~min}$ treatment of $\mathrm{I}$ is reproduced in Figure 3a. There are numerous peaks, besides that due to residual I, which are attributed to organic species formed along the oxidation pathways of $\mathrm{I}$ to $\mathrm{CO}_{2}$. Fig. $3 \mathrm{~b}$ shows the time/energy profiles of the intensity of the major peaks detected in the analysis of solution samples withdrawn at various treatment times. All peaks behave similarly in that their intensity, which is proportional to the corresponding compound concentration in solution, grows from zero in the untreated solution to a maximum at specific treatment times and then decays. This behavior is typical of reaction intermediates which are in turn decomposed by the plasma generated reactive species leading eventually to complete mineralization of organic carbon to $\mathrm{CO}_{2}$. The characterization of the major intermediates detected in our experiments was based on MS and MS/MS analyses and on the comparison of our results with published data on oxidation pathways of imidacloprid. Most useful was also a detailed study on the fragmentation behavior of protonated imidacloprid [50], fragmentation which affects initially the nitro-guanidine moiety via primary losses of $\mathrm{N}_{2} \mathrm{O}(44 \mathrm{Da}), \mathrm{NO}_{2}(46 \mathrm{Da})$ and $\mathrm{HNO}_{2}(47 \mathrm{Da})$. The three major intermediates detected in our system, I3, I4 and I5 are isomers all giving in the mass spectrum a signal at $\mathrm{m} / \mathrm{z} 270$ attributed to their protonated species, $[\mathrm{M}+\mathrm{H}]^{+}$. Considering the mass increase of $14 \mathrm{Da}$ with respect to $\mathrm{I}$, it is reasonable to identify these isomeric species as early products of oxidation in which a methylene unit $\left(-\mathrm{CH}_{2}-\right)$ has been converted into a carbonyl group $(>\mathrm{C}=\mathrm{O})$. As there are three such units in imidacloprid, products I3 - I5 can be associated to the structures shown in Scheme 1, although it is no possible to establish which is which. The MS/MS spectra of the protonated form, $[\mathrm{M}+\mathrm{H}]^{+}$, of I3 - I5 (Fig.s 3c)-3e)) show the same characteristic losses described above for 
protonated imidacloprid. Interestingly, these intermediates were also detected in a study on the ozonation of imidacloprid, in which it was proposed that they are formed from the corresponding alcohols as shown in Scheme 1 [15]. A similar path is likely occurring in our process as confirmed by the detection of at least one of such hydroxylated precursors (peak I2 in the chromatogram of Fig. 3a), characterized by an $[\mathrm{M}+\mathrm{H}]^{+}$signal at $\mathrm{m} / \mathrm{z} 272$. Finally, intermediate $\mathrm{I}$, giving an $[\mathrm{M}+\mathrm{H}]^{+}$ signal at m/z 230, was also identified as shown in Scheme 1, as suggested by Bourgin et al [15].

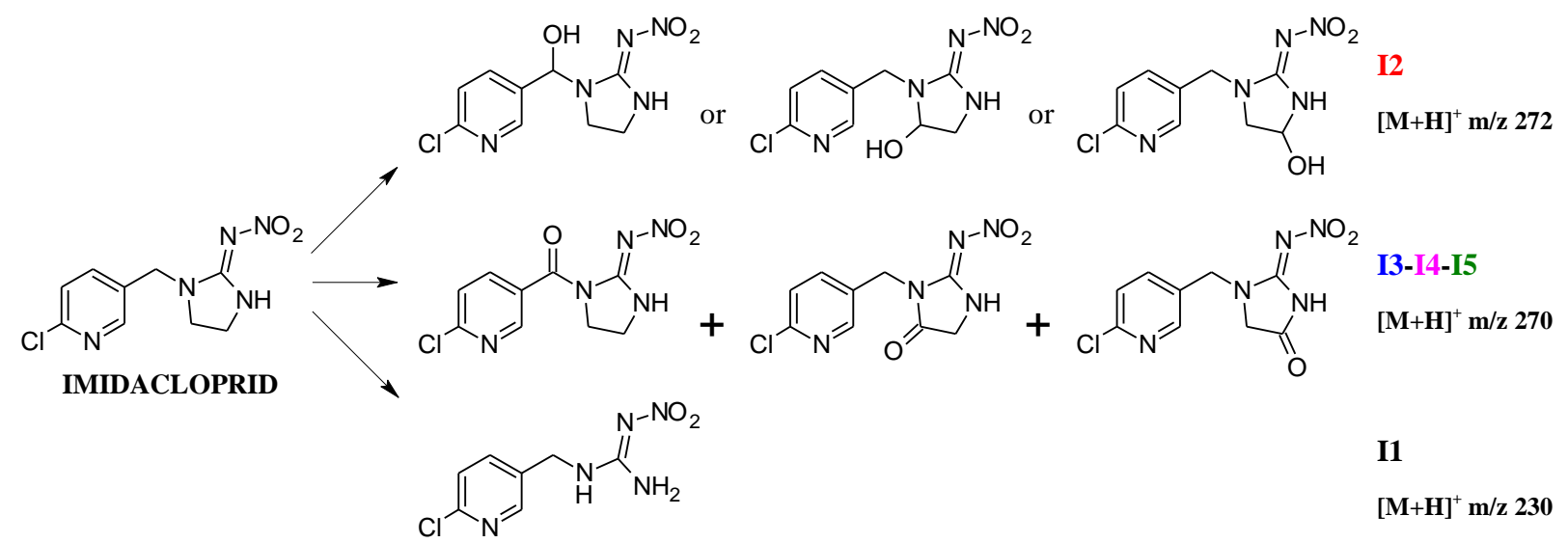

\section{Scheme 1}

Table 2. Mineralization yield of Imidacloprid (I) and Thiamethoxam (T) in NTP advanced oxidation process. $^{a)}$

\begin{tabular}{cccc}
\hline Insecticide $(\mathbf{M})$ & Carbon $(\boldsymbol{\%})^{b)}$ & Chlorine $(\boldsymbol{\%})^{c)}$ & Sulfur $(\boldsymbol{\%})^{c)}$ \\
\hline I $\left(1 \cdot 10^{-5}\right)$ & $95 \pm 11$ & $91 \pm 10$ & - \\
I $\left(1 \cdot 10^{-4}\right)$ & $65 \pm 6$ & $68 \pm 7$ & - \\
$\mathrm{T}\left(1 \cdot 10^{-5}\right)$ & $83 \pm 12$ & $112 \pm 17$ & $100 \pm 30$ \\
$\mathrm{~T}\left(1 \cdot 10^{-4}\right)$ & $75 \pm 4$ & $69 \pm 9$ & $79 \pm 7$ \\
\hline
\end{tabular}

${ }^{a}$ In all these experiments the treatment time was $5 \mathrm{hr} .{ }^{b}$ Determined by analysis of residual organic carbon in treated solution with TOC analyzer. ${ }^{c)}$ Determined by ion chromatography of treated solution. 

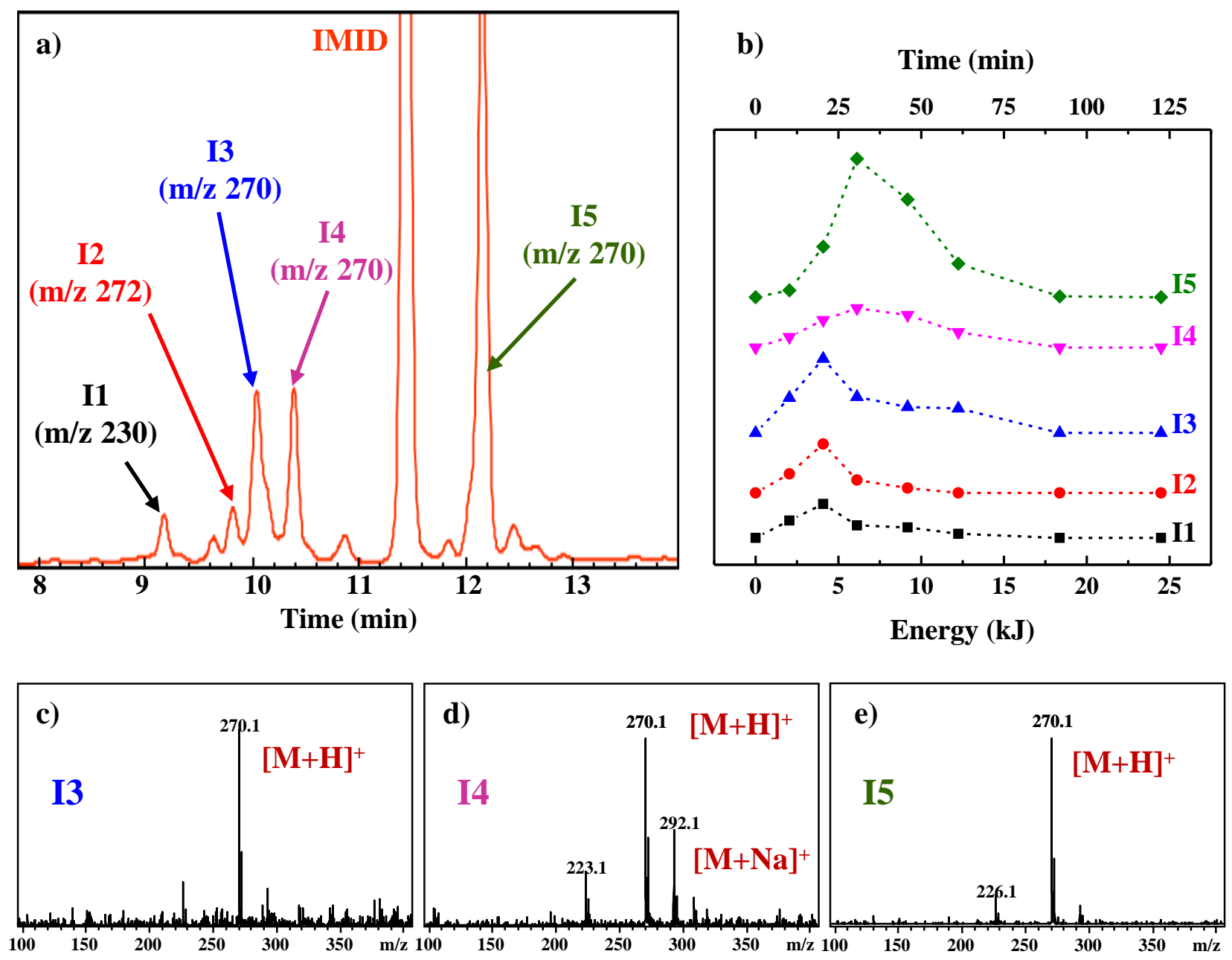

Figure 3. a) HPLC-UV chromatogram recorded at $270 \mathrm{~nm}$ of a solution of $\mathrm{I}\left(10^{-4} \mathrm{M}\right)$ treated in the NTP plasma reactor for $30 \mathrm{~min}$. b) Time and energy profiles of the intensity of major reaction intermediates, labeled as in Fig. 3a. c) - e) Mass spectra of and inferred structures for major intermediates I3 - I5. 

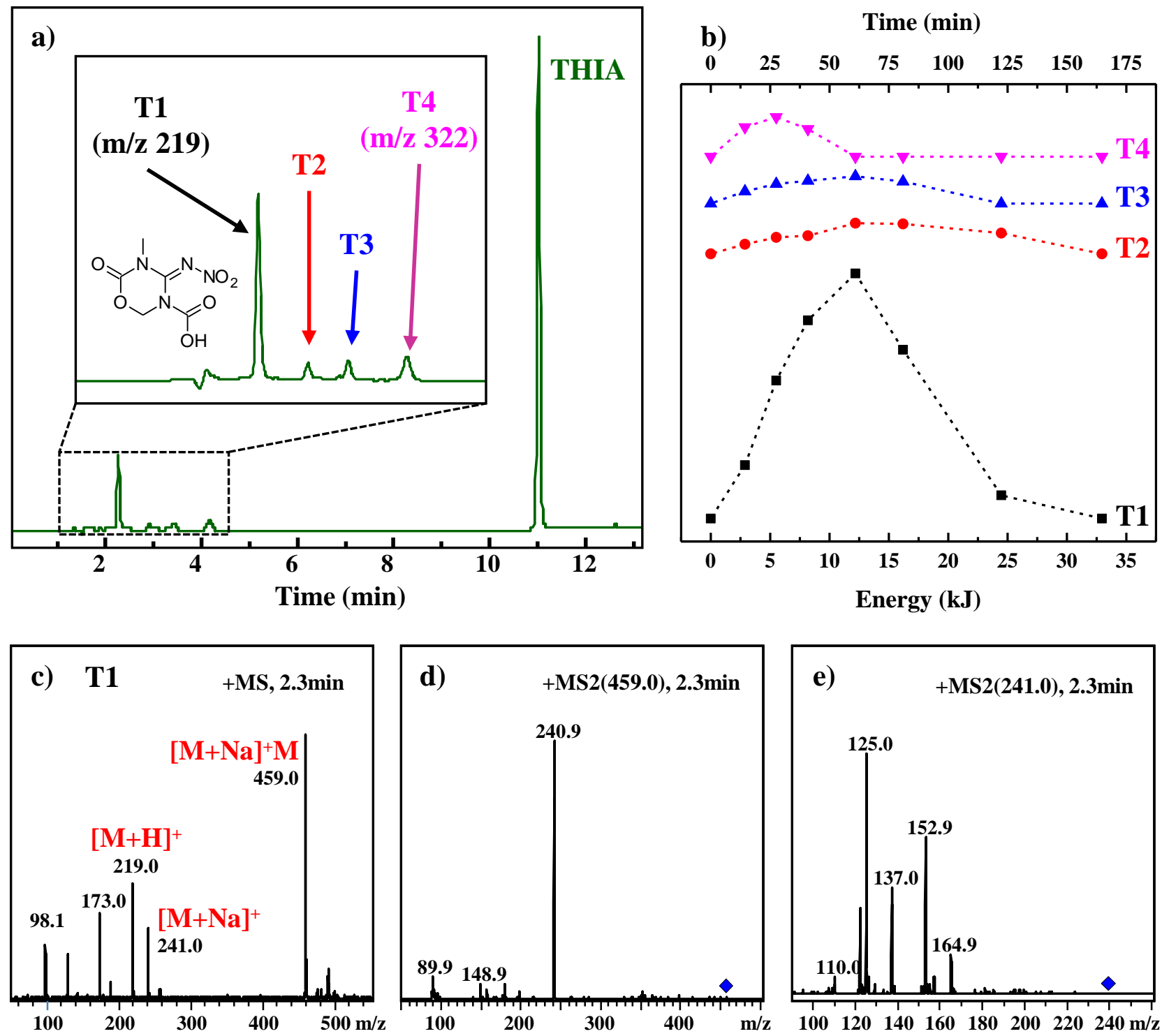

Figure 4. a) HPLC-UV chromatogram recorded at $270 \mathrm{~nm}$ of a solution of $\mathrm{T}\left(1 \cdot 10^{-4} \mathrm{M}\right)$ treated in the NTP plasma reactor for $30 \mathrm{~min}$. b) Time and energy profiles of the intensity of major reaction intermediates, labeled as in Fig. 4a. c) Mass spectrum of intermediate T1; d) MS/MS spectrum of ion with $\mathrm{m} / \mathrm{z} 459$, identified as $[\mathrm{M}+\mathrm{Na}]^{+} \cdot \mathrm{M}$; e) MS/MS spectrum of ion with $\mathrm{m} / \mathrm{z} 241$, identified as $[\mathrm{M}+\mathrm{Na}]^{+}$.

Analogous product studies were carried out for thiamethoxam (Fig. 4). There appears to be only one relatively abundant intermediate formed in our NTP-induced process, labeled T1 on the chromatogram shown in Fig. 4a, all other detected species being way less abundant at any treatment time (Fig. 4b). T1 and all the other less abundant products appear to reach a maximum concentration during the process and then to decay completely at longer treatment times (Fig. 4b). The positive ion ESI mass spectrum of T1 (Fig. 4c) shows lack of chlorine in this compound and an intense signal at $\mathrm{m} / \mathrm{z} 459$ which is attributed to an ionic complex formed, upon ionization in the ESI 
source, by two molecules of $\mathrm{T} 1$ and a sodium cation, abbreviated here as $[\mathrm{M}+\mathrm{Na}]^{+} \cdot \mathrm{M}$. The presence of intense signals at $\mathrm{m} / \mathrm{z} 241\left([\mathrm{M}+\mathrm{Na}]^{+}\right)$and $\mathrm{m} / \mathrm{z} 219\left([\mathrm{M}+\mathrm{H}]^{+}\right)$is consistent with this interpretation and suggests that $\mathrm{T} 1$ has a molecular mass of 218. Further support for this assignment and some structural insight come from the MS/MS spectra of the ions at m/z $459\left([\mathrm{M}+\mathrm{Na}]^{+} \cdot \mathrm{M}\right)$ and $\mathrm{m} / \mathrm{z} 241$ $\left([\mathrm{M}+\mathrm{Na}]^{+}\right)$, shown in Fig.s $4 \mathrm{~d}$ and $4 \mathrm{e}$, respectively. The $[\mathrm{M}+\mathrm{Na}]^{+} \cdot \mathrm{M}$ complex dissociates by loss of a neutral $\mathrm{M}$ molecule to give $[\mathrm{M}+\mathrm{Na}]^{+}$(peak at $\mathrm{m} / \mathrm{z} 241$, Fig. $4 \mathrm{~d}$ ). The sodiated species, $[\mathrm{M}+\mathrm{Na}]^{+}$, forms numerous fragment ions via neutral losses of $46 \mathrm{Da}\left(\mathrm{NO}_{2}\right), 30 \mathrm{Da}\left(\mathrm{CH}_{2}=\mathrm{O}\right), 28 \mathrm{Da}(\mathrm{CO})$ and $42 \mathrm{Da}$. Interestingly, a product with molecular mass of $218 \mathrm{Da}$ was also observed by Sojic et al. but not identified in their study of thiamethoxam degradation by $\mathrm{UV}, \mathrm{O}_{3}$ and $\mathrm{UV} / \mathrm{O}_{3}$ processes [23]. This product gave a signal at m/z 217 in negative ion ionization mode indicating the presence of acidic functional groups. Based on these indications from the literature and on the fragmentation behavior reported above we suggest the $\mathrm{C}_{5} \mathrm{H}_{6} \mathrm{~N}_{4} \mathrm{O}_{6}$ elemental composition for $\mathrm{T} 1$ and speculate as possible structure that shown in Fig. 4.

As for the other minor intermediates detected (T2 - T4, Fig.s 4a-b), the available information is not sufficient for unambiguous identifications. It is however interesting to note that the mass spectrum of our product T2 matches that reported by Sojic et al. for an unidentified intermediate of molecular mass of $155 \mathrm{Da}$ [23]. In contrast, there is no match with the intermediate products reported by Li et al. in their paper on DBD induced degradation of thiamethoxam [43], the structures of which appear to have been drawn improperly and assigned arbitrarily.

\section{2 - Experiments with I and T treated in the same solution}

Next, solutions containing both $\mathrm{I}$ and $\mathrm{T}$ were treated and analyzed. Table 2 and Figure 5a summarize the results of these experiments in which the total initial concentration of pollutants (I+ $\mathrm{T})$ in solution was the same $\left(\mathrm{ca} 1 \cdot 10^{-4} \mathrm{M}\right)$ but their molar ratio was changed.

Table 2. Energy constant $\left(k_{E}\right)$ for Imidacloprid (I) and Thiametoxam (T) decay in NTP advanced oxidation process when treated together within the same solution.

\begin{tabular}{cccc}
\hline $\boldsymbol{C}_{\boldsymbol{0}} \boldsymbol{t o t a l}^{a)}(\mathbf{M})$ & $\chi_{T}{ }^{b)}$ & \multicolumn{2}{c}{$\boldsymbol{k}_{\boldsymbol{E}}\left(\mathbf{k J} \mathbf{J}^{-\mathbf{1}}\right)$} \\
\cline { 3 - 4 } & & $\mathbf{I}$ & $\mathbf{T}$ \\
\hline $1.13 \cdot 10^{-4}$ & 0.50 & $1.51 \pm 0.11$ & $1.53 \pm 0.12$ \\
$1.06 \cdot 10^{-4}$ & 0.70 & $1.32 \pm 0.16$ & $1.36 \pm 0.17$ \\
$6.96 \cdot 10^{-4}$ & 0.31 & $1.94 \pm 0.14$ & $2.01 \pm 0.14$ \\
$1.08 \cdot 10^{-4}$ & 0.53 & $1.40 \pm 0.17$ & $1.47 \pm 0.16$ \\
$1.07 \cdot 10^{-4}$ & 0.95 & $1.20 \pm 0.13$ & $1.19 \pm 0.12$ \\
$1.13 \cdot 10^{-4}$ & 0.50 & $1.41 \pm 0.15$ & $1.41 \pm 0.16$ \\
\hline
\end{tabular}



$1.11 \cdot 10^{-4}$
0.72
$1.28 \pm 0.17$
$1.27 \pm 0.17$

a) The sum of I and T molarity. ${ }^{\boldsymbol{b})}$ The molar fraction of T. The molar fraction of I is $1-\chi_{T}$.
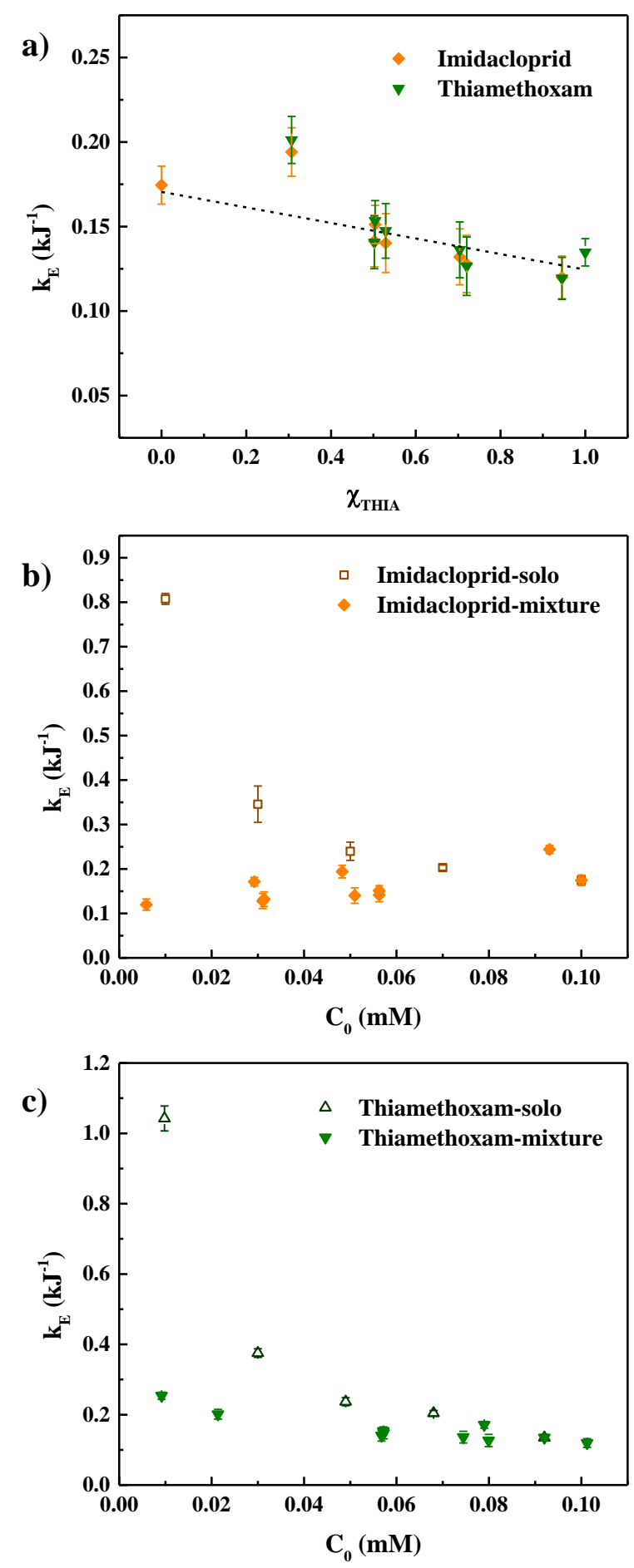

Figure 5. Energy constants for $I$ and $T$ as a function of: a) $\chi_{T}$, the molar fraction of $T$ in experiments in which I and $\mathrm{T}$ were treated together with a total initial concentration of $c a 1 \cdot 10^{-4} \mathrm{M}$. The black dashed line is the linear fit of the experimental data. The data for $\chi_{\text {THIA }}=0.3$ were not included in the fitting because the total concentration of the pollutants in that experiment was significantly lower than $1 \cdot 10^{-4} \mathrm{M}$; b) $C_{0}$, the initial concentration of I treated individually (open symbol) and in mixture with $\mathrm{T}$ (closed symbol) at a total 
concentration of $1 \cdot 10^{-4} \mathrm{M}$; c) $C_{0}$, the initial concentration of $\mathrm{T}$ treated individually (open symbol) and in mixture with I (closed symbol) at a total concentration of $1 \cdot 10^{-4} \mathrm{M}$.

It is interesting to note how in these mixtures each insecticide decays with an efficiency which appears to be very similar to that of the other one and, most importantly, little dependent on the insecticide initial concentration (Fig. 5a). This behavior is in striking contrast with that observed when I and $\mathrm{T}$ are treated alone, as is evident in the plots of Fig.s 5b and 5c, respectively. These observations are consistent with the mechanism mentioned above [49] and can be rationalized as follows. Given that when tested separately I and T behave quite similarly ( $k_{E}$ data in Table 1) and react with the same plasma generated reactive species, indicated here as $X$, with similar rate constants (plots of Fig. 2), it is expected that they should be equally effective in competing for X. Thus, the decay of each should depend on the overall solution concentration, i.e. [I]+[T], regardless of their molar fraction. From the kinetic point of view, therefore, any mixed solution of $\mathrm{I}+\mathrm{T}$ behaves as if it contained only I or only T: as long as the solution overall initial concentration is the same $\left([\mathrm{I}]_{0}+[\mathrm{T}]_{0}=1 \cdot 10^{-4} \mathrm{M}\right)$, both $\mathrm{I}$ and $\mathrm{T}$ react with the same efficiency they display when treated alone at $1 \cdot 10^{-4} \mathrm{M}$. The data in Fig.s 5 are consistent with this interpretation. The points which deviate from the others, those for $\chi_{\text {THIA }}=0.3$, refer to an experiment in which the total initial concentration $\left([\mathrm{I}]_{0}+[\mathrm{T}]_{0}\right)$ was significantly lower $\left(0.7 \cdot 10^{-4} \mathrm{M}\right.$ instead of $\left.1 \cdot 10^{-4} \mathrm{M}\right)$. The higher $k_{E}$ values determined in this experiment are thus fully consistent with the expectation of greater efficiency at lower concentration (Fig. 2). Obviously, different outcomes from what found in this work are expected in case the two competitors have different reactivities.

\section{4 - Conclusions}

The results of this study highlight the potential of NTP-based AOP in the degradation of persistent water soluble neonicotinoid insecticides, imidacloprid and thiamethoxam, and prove that high extents of mineralization can be achieved in these treatments. The efficiency of thiamethoxam degradation, measured by the $\mathrm{G}_{50}$ indicator, is considerably better in our experiments than in those reported in the literature for an NTP process induced by DBD discharge in the presence of $\mathrm{TiO}_{2}$ [43]. These findings are encouraging considering that the concentrations of neonicotinoids in the environment are much lower than those used in this work and that the rates of plasmachemical advanced oxidation and of mineralization increase as the pollutants initial concentration is decreased. Moreover, there is still wide margin for improving the process efficiency by proper engineering and optimization of the reactor/plasma source design [34]. An element of novelty of our work is the study of the competition for the plasma reactive species by the two insecticides when they are treated together in the same solution. Based on the results of kinetic studies run with 
solutions of I and T treated individually at different initial concentrations, it can be concluded that the degradation of both is initiated by the attack of the same reactive species, notably the $\mathrm{OH}$ radical which was identified and determined in previous works with this NTP reactor [42]. When treated together, due to their similar reactivities, imidacloprid and thiamethoxam compete equally efficiently for the reactive species so that the decay of each depends on the overall solution concentration, i.e. $[\mathrm{I}]+[\mathrm{T}]$, regardless of their molar fraction.

\section{Acknowledgments}

We thank Remy Ravaute for help in conducting some of the experiments. Financial support by the University of Padova is gratefully acknowledged (grant SID 2017 - and grant CPDR152275 Progetto per Assegni di Ricerca Junior 2015).

\section{References}

1. Stehle S, Bub S, Schulz R (2018) Compilation and analysis of global surface water concentrations for individual insecticide compounds. Sci Total Environ 639:516-525. https://doi.org/10.1016/j.scitotenv.2018.05.158

2. Huseth AS, Groves RL (2014) Environmental fate of soil applied neonicotinoid insecticides in an irrigated potato agroecosystem. PLoS One 9:e97081. https://doi.org/10.1371/journal.pone.0097081

3. Morrissey CA, Mineau P, Devries JH, et al (2015) Neonicotinoid contamination of global surface waters and associated risk to aquatic invertebrates: A review. Environ Int 74:291303. https://doi.org/10.1016/j.envint.2014.10.024

4. Sánchez-Bayo F, Hyne RV (2014) Detection and analysis of neonicotinoids in river waters Development of a passive sampler for three commonly used insecticides. Chemosphere 99:143-151. https://doi.org/10.1016/j.chemosphere.2013.10.051

5. Goulson D (2013) An overview of the environmental risks posed by neonicotinoid insecticides. J Appl Ecol 50:977-987. https://doi.org/10.1111/1365-2664.12111

6. Barbosa MO, Moreira NFF, Ribeiro AR, et al (2016) Occurrence and removal of organic micropollutants: An overview of the watch list of EU Decision 2015/495. Water Res 94:257279. https://doi.org/10.1016/j.watres.2016.02.047

7. Klarich KL, Pflug NC, DeWald EM, et al (2017) Occurrence of neonicotinoid insecticides in finished drinking water and fate during drinking water treatment. Environ Sci Technol Lett 
4:168-173. https://doi.org/10.1021/acs.estlett.7b00081

8. Acero JL, Real FJ, Javier Benitez F, Matamoros E (2019) Degradation of neonicotinoids by UV irradiation: Kinetics and effect of real water constituents. Sep Purif Technol 211:218226. https://doi.org/10.1016/j.seppur.2018.09.076

9. Kitsiou V, Filippidis N, Mantzavinos D, Poulios I (2009) Heterogeneous and homogeneous photocatalytic degradation of the insecticide imidacloprid in aqueous solutions. Appl Catal B Environ 86:27-35. https://doi.org/10.1016/j.apcatb.2008.07.018

10. Yin K, Deng Y, Liu C, et al (2018) Kinetics, pathways and toxicity evaluation of neonicotinoid insecticides degradation via UV/chlorine process. Chem Eng J 346:298-306. https://doi.org/10.1016/j.cej.2018.03.168

11. Papoutsakis S, Pulgarin C, Oller I, et al (2016) Enhancement of the Fenton and photo-Fenton processes by components found in wastewater from the industrial processing of natural products: The possibilities of cork boiling wastewater reuse. Chem Eng J 304:890-896. https://doi.org/10.1016/j.cej.2016.07.021

12. Turabik M, Oturan N, Gözmen B, Oturan MA (2014) Efficient removal of insecticide "imidacloprid" from water by electrochemical advanced oxidation processes. Environ Sci Pollut Res 21:8387-8397. https://doi.org/10.1007/s11356-014-2788-9

13. Zhao H, Qian L, Chen Y, et al (2018) Selective catalytic two-electron $\mathrm{O}_{2}$ reduction for onsite efficient oxidation reaction in heterogeneous electro-Fenton process. Chem Eng J 332:486498. https://doi.org/10.1016/j.cej.2017.09.093

14. Iglesias O, Gómez J, Pazos M, Sanromán MA (2014) Electro-Fenton oxidation of imidacloprid by Fe alginate gel beads. Appl Catal B Environ 144:416-424. https://doi.org/10.1016/j.apcatb.2013.07.046

15. Bourgin M, Violleau F, Debrauwer L, Albet J (2011) Ozonation of imidacloprid in aqueous solutions: Reaction monitoring and identification of degradation products. J Hazard Mater 190:60-68. https://doi.org/10.1016/j.jhazmat.2011.02.065

16. Peng Q, Zhao H, Qian L, et al (2015) Design of a neutral photo-electro-Fenton system with 3D-ordered macroporous $\mathrm{Fe}_{2} \mathrm{O}_{3} /$ carbon aerogel cathode: High activity and low energy $\begin{array}{llll}\text { consumption. } & \text { Appl } & \text { Catal 174-175:157-166. }\end{array}$ https://doi.org/10.1016/j.apcatb.2015.02.031

17. Tang J, Huang X, Huang X, et al (2012) Photocatalytic degradation of imidacloprid in 
aqueous suspension of $\mathrm{TiO}_{2}$ supported on H-ZSM-5. Environ Earth Sci 66:441-445. https://doi.org/10.1007/s12665-011-1251-1

18. Wang Y, Zhao H, Li M, et al (2014) Magnetic ordered mesoporous copper ferrite as a heterogeneous Fenton catalyst for the degradation of imidacloprid. Appl Catal B Environ 147:534-545. https://doi.org/10.1016/j.apcatb.2013.09.017

19. Žabar R, Komel T, Fabjan J, et al (2012) Photocatalytic degradation with immobilised TiO2 of three selected neonicotinoid insecticides: Imidacloprid, thiamethoxam and clothianidin. Chemosphere 89:293-301. https://doi.org/10.1016/j.chemosphere.2012.04.039

20. Zaror C, Segura C, Mansilla H, et al (2010) Kinetic study of Imidacloprid removal by advanced oxidation based on photo-Fenton process. Environ Technol 31:1411-1416. https://doi.org/10.1080/09593331003680926

21. Papoutsakis S, Brites-Nóbrega FF, Pulgarin C, Malato S (2015) Benefits and limitations of using $\mathrm{Fe}(\mathrm{III})$-EDDS for the treatment of highly contaminated water at near-neutral $\mathrm{pH}$. J $\begin{array}{llll}\text { Photochem Photobiol A } & \text { A }\end{array}$ https://doi.org/10.1016/j.jphotochem.2015.01.013

22. Zhao Q, Ge Y, Zuo P, et al (2016) Degradation of Thiamethoxam in aqueous solution by ozonation: Influencing factors, intermediates, degradation mechanism and toxicity assessment. Chemosphere 146:105-112. https://doi.org/10.1016/j.chemosphere.2015.09.009

23. Šojić D, Despotović V, Orčić D, et al (2012) Degradation of thiamethoxam and metoprolol by $\mathrm{UV}, \mathrm{O}_{3}$ and $\mathrm{UV} / \mathrm{O}_{3}$ hybrid processes: Kinetics, degradation intermediates and toxicity. $\mathrm{J}$ Hydrol 472-473:314-327. https://doi.org/10.1016/j.jhydrol.2012.09.038

24. Mir NA, Khan A, Muneer M, Vijayalakhsmi S (2013) Photocatalytic degradation of a widely used insecticide Thiamethoxam in aqueous suspension of $\mathrm{TiO}_{2}$ : Adsorption, kinetics, product analysis and toxicity assessment. Sci Total Environ 458-460:388-398. https://doi.org/10.1016/j.scitotenv.2013.04.041

25. Miklos DB, Remy C, Jekel M, et al (2018) Evaluation of advanced oxidation processes for water and wastewater treatment - A critical review. Water Res 139:118-131. https://doi.org/10.1016/j.watres.2018.03.042

26. Bruggeman PJ, Kushner MJ, Locke BR, et al (2016) Plasma-liquid interactions: A review and roadmap. Plasma Sources Sci Technol 25:053002. https://doi.org/10.1088/09630252/25/5/053002 
27. Jiang B, Zheng J, Qiu S, et al (2014) Review on electrical discharge plasma technology for wastewater remediation. Chem Eng J 236:348-368. https://doi.org/10.1016/j.cej.2013.09.090

28. Vanraes P, Nikiforov AY, Leys C (2016) Electrical Discharge in Water Treatment Technology for Micropollutant Decomposition. In: Mieno T (ed) Plasma Science and Technology - Progress in Physical States and Chemical Reactions. InTech, pp 429-478

29. Foster JE, Mujovic S, Groele J, Blankson IM (2018) Towards high throughput plasma based water purifiers: Design considerations and the pathway towards practical application. J Phys D Appl Phys 51:293001. https://doi.org/10.1088/1361-6463/aac816

30. Marotta E, Schiorlin M, Ren X, et al (2011) Advanced oxidation process for degradation of aqueous phenol in a dielectric barrier discharge reactor. Plasma Process Polym 8:867-875. https://doi.org/10.1002/ppap.201100036

31. Bosi FJ, Tampieri F, Marotta E, et al (2018) Characterization and comparative evaluation of two atmospheric plasma sources for water treatment. Plasma Process Polym 15:1700130. https://doi.org/10.1002/ppap.201700130

32. Tampieri F, Giardina A, Bosi FJ, et al (2018) Removal of persistent organic pollutants from water using a newly developed atmospheric plasma reactor. Plasma Process Polym 15:1700207. https://doi.org/10.1002/ppap.201700207

33. Ceriani E, Marotta E, Schiorlin M, et al (2018) A versatile prototype plasma reactor for water treatment supporting different discharge regimes. J Phys D Appl Phys 51:274001. https://doi.org/10.1088/1361-6463/aac7cd

34. Stratton GR, Dai F, Bellona CL, et al (2017) Plasma-Based Water Treatment: Efficient Transformation of Perfluoroalkyl Substances in Prepared Solutions and Contaminated Groundwater. Environ Sci Technol 51:1643-1648. https://doi.org/10.1021/acs.est.6b04215

35. Panorel I, Kornev I, Hatakka H, Preis S (2011) Pulsed corona discharge for degradation of aqueous humic substances. Water Sci Technol Water Supply 11:238-245. https://doi.org/10.2166/ws.2011.045

36. Magureanu M, Mandache NB, Parvulescu VI (2015) Degradation of pharmaceutical compounds in water by non-thermal plasma treatment. Water Res 81:124-136. https://doi.org/10.1016/j.watres.2015.05.037

37. Krishna S, Ceriani E, Marotta E, et al (2016) Products and mechanism of verapamil removal in water by air non-thermal plasma treatment. Chem Eng J 292:35-41. 
https://doi.org/10.1016/j.cej.2016.01.108

38. Hsieh K, Wang H, Locke BR (2016) Analysis of a gas-liquid film plasma reactor for organic $\begin{array}{llll}\text { compound } & \text { oxidation. } & \text { J } & \text { Hazard }\end{array}$ https://doi.org/10.1016/j.jhazmat.2016.05.053

39. Cadorin BM, Tralli VD, Ceriani E, et al (2015) Treatment of methyl orange by nitrogen nonthermal plasma in a corona reactor: The role of reactive nitrogen species. J Hazard Mater 300:754-764. https://doi.org/10.1016/j.jhazmat.2015.08.009

40. Magureanu M, Bradu C, Parvulescu VI (2018) Plasma processes for the treatment of water contaminated with harmful organic compounds. J Phys D Appl Phys 51:313002. https://doi.org/10.1088/1361-6463/aacd9c

41. Giardina A, Tampieri F, Marotta E, Paradisi C (2018) Air non-thermal plasma treatment of Irgarol 1051 deposited $\quad \mathrm{TiO}_{2}$. Chemosphere 210:653-661. https://doi.org/10.1016/j.chemosphere.2018.07.012

42. Nani L, Tampieri F, Ceriani E, et al (2018) ROS production and removal of the herbicide metolachlor by air non-thermal plasma produced by DBD, DC- and DC+ discharges implemented within the same reactor. J Phys D Appl Phys 51:274002. https://doi.org/10.1088/1361-6463/aab8b9

43. Li S, Liu L, Ma X, Li Y (2016) Degradation of thiamethoxam in wastewater by low temperature plasma. J Adv Oxid Technol 19:347-357. https://doi.org/10.1515/jaots-20160219

44. Von Gunten U (2018) Oxidation Processes in Water Treatment: Are We on Track? Environ Sci Technol 52:5062-5075. https://doi.org/10.1021/acs.est.8b00586

45. Zazo JA, Casas JA, Mohedano AF, et al (2005) Chemical pathway and kinetics of phenol oxidation by Fenton's reagent. Environ Sci Technol 39:9295-9302. https://doi.org/10.1021/es050452h

46. Malik MA (2010) Water purification by plasmas: Which reactors are most energy efficient? Plasma Chem Plasma Process 30:21-31. https://doi.org/10.1007/s11090-009-9202-2

47. Marotta E, Ceriani E, Shapoval V, et al (2011) Characterization of plasma-induced phenol advanced oxidation process in a DBD reactor. EPJ Appl Phys 55:13811. https://doi.org/10.1051/epjap/2011110024

48. Madureira J, Ceriani E, Pinhão N, et al (2017) Oxidation of clofibric acid in aqueous solution 
using a non-thermal plasma discharge or gamma radiation. Chemosphere 187:395-403. https://doi.org/10.1016/j.chemosphere.2017.08.109

49. Slater RC, Douglas-Hamilton DH (1981) Electron-beam-initiated destruction of low concentrations of vinyl chloride in carrier gases. J Appl Phys 52:5820-5828. https://doi.org/10.1063/1.329476

50. Donald WA, Leeming MG, O'Hair RAJ (2012) Gas-phase ion chemistry of the pesticide imidacloprid: Proton driven radical fragmentation of the nitro-guanidine functional group. Int J Mass Spectrom 316-318:91-99. https://doi.org/10.1016/j.ijms.2012.01.017 